\title{
Modularity of Mind and Second Language Acquisition
}

\author{
Houman Bijani \\ Islamic Azad University, Science and Research Branch, Tehran, Iran \\ Email: houman.bijani@gmail.com \\ Alaeddin Nahvi \\ Art University, Tehran, Iran
}

\begin{abstract}
The concept of modularity has become significant in philosophy and psychology since the early 1980s, following the publication of Fodor's ground-breaking book The Modularity of Mind (1983). In the twenty-five years since the term 'module' and its cognates first entered the lexicon of cognitive science, the conceptual and theoretical landscape in this area has changed thoroughly. A critical issue in this regard has been the development of evolutionary psychology, whose proponents argue that the architecture of the mind is more pervasively modular than the Fodorian perspective allows. Where Fodor (2005) draws the line of modularity at the low-level systems underlying perception and language, post-Fodorian theorists such as Carruthers (2008) contend that the mind is modular through and through, that is, up to and including the high-level systems responsible for thought. The concept of modularity has also played a role in recent debates in epistemology, philosophy of language, and other core areas of philosophy.
\end{abstract}

Index Terms - modularity of mind, Chomskyan Modularity, Fodorian Modularity, Massive Modularity

\section{INTRODUCTION}

It has been recognized for two thousand years that language faculty can be impaired as the result of damage to different parts of the brain, however, it is only since the middle of the nineteenth century that scientists obtained systematic evidence for the lateralization of language faculty; that is, according to Smith (1999), linguistic ability is largely supported by the left hemisphere. However, it would be ridiculous to expect a single simple relation between mind and brain. In linguistics, as argued by Jenkins (2000), the view of brain as a tabula rasa for language has been rejected by the view that brain consists of highly specialized language areas. Different linguistic functions are typically localized differently with the left hemisphere taking the major responsibility for syntax and the right one for semantic and pragmatic processes (Smith, 1999). One issue of controversy in the neurology of human brain and mind, according to Mitchell and Myles (2004) has been the extent to which the mind should be viewed as modular or unitary. That is, should we see the mind as a single, flexible organism with a general set of procedures for learning and storing different kinds of knowledge or is it understood as a set of modules? In this respect, modularity, as defined by Gregg (2003), is "comparatively an autonomous subsystem within a larger system, which acts more or less independently of other subsystems, and has structures and functions that are more or less recognizably different from those of other subsystems" (p. 98).

Modularity - the theory that there is a unique language 'organ' distinct from other cognitive systems and abilitieswas central to much of Fromkin's work, and her support for the theory of a genetically determined language faculty placed her within the general scope of Chomskyan generative linguistics. However, her work was often on the bridge between linguistics and other disciplines (aphasia studies, neurobiology, psychology), and so, except for debates over modularity, she was not a core figure in controversies of theoretical linguistics.

Modularity in language according to Ellis (1997) could be defined as "the existence of separate language faculty and different components of language in distinct cognitive modules each differing in the nature of its representations" ( $p$. 71). Many linguists and psycholinguists such as Chomsky, believe that modularity is mostly associated with nativism; however, as claimed by Botterill and Carruthers (1999), nativism is about how cognition develops; whereas, modularity is matter of how cognitive processing is organized.

According to the modularity hypothesis, once a syntactic structure and thematic roles have been assigned, the construction of a full interpretation of a sentence lies in the domain of central, domain general, processes which have access to world knowledge. For this reason, processing architecture ceases to be an issue when these higher-level aspects of comprehension are considered. Early research in this area was concerned with the kind of representations that are formed as the products of the comprehension process, exploring people's memory for sentences or short texts. Theories of processing are less developed than for lower-level aspects of language, and as Gernsbacher and Foertsch (1999) remark, are so similar in spirit that they are difficult to distinguish empirically.

According to Sugayama and Hudson (2005), there is a strong and a weak version of language modularity. Based on 
the strong version of modularity, mind is made up of several different modules and language is just a single module. One alternative to the strong version of modularity is the weak version which offers no modularity at all with the mind is viewed as a single whole.

Gregg (2003) believes that, there are two levels of analysis for the concept of modularity in second language:

- Anatomical modularity: which claims that L2 knowledge is localized in a specific well-defined area of brain. Based on anatomical modularity, second language module is different from first language module; that is, there are two separate cognitive modules for the first and second language.

- Cognitive modularity: which claims that L2 knowledge is a module within a larger system of knowledge.

Putting aside anatomical modularity, as argued by Trask (1999), we can distinguish between two types of cognitive modularity which since the early 1980s, has become prominent in linguistics and cognitive science in at least two ways. First, the American philosopher Jerry Fodor has been arguing that human mind is itself modular, that is, it consists of a number of specialized subcomponents for handling different tasks, such as speaking and seeing. Second, the American linguist Noam Chomsky has been arguing that the human language faculty is modular, that is, it must consist of a fairly large number of semi-autonomous units, each of which responsible for certain particular aspects of our linguistic competence.

\section{- Chomskyan Modularity}

Chomsky's work over several decades has provided a powerful evidence that language faculty consists of separate modules (McGilvray, 2005). Chomsky claims that there are two different notions of modularity:

- Language faculty is a module of the mind, distinct from moral judgment, music, and mathematics; and

- The language module itself divides up into submodules, relating to sound, structure, and meaning.

According to Chomskian or intentional modularity, language faculty is modular and thus autonomous from the module of mind in a way that it comprises structures and conforms to principles not found in other modules (Chomsky, 1972). Chomsky believes that even grammar itself can be seen as modular; that is to say, what is grammatical and what is not grammatical in a given language is not determined by a single set of global grammatical principles but rather by a number of modules. The evidence for this modularity, according to Zobl (1989), comes from either brain damage or neurological disorders which affect language differently from other mental functions. Chomsky argues that in human mind, there is a language faculty, or grammar module, which is responsible for grammatical knowledge, and that other modules handle other kinds of knowledge. Chomsky's view is that not only is language too complex to be learnt from environmental exposure (his criticism of Skinner); but also it is also too distinctive in its structure to be learnable by one whole general cognitive means.

Chomsky believes, as mentioned by Van Valin (1991), that the linguistic competence module is divided into two different modules, grammatical module and pragmatic module. Grammatical module encompasses knowledge of grammar; however, the pragmatic module includes logic of conversation which places language in use. Chomsky further, according to Dudai (2002), declared that language acquisition depends on an innate, species-specific module that is distinct from general intelligence. Chomsky believes that language is not only an input system, but also it is an output system responsible for verbal and written expression of thought. The input and output system correlate and share a common cognitive central system. Chomsky, in contrast to Fodor's opinion, believes that the internal workings of the language module are not obvious. The significant characteristics of Chomskian modularity, as claimed by Brook and Akins (2005), is that not only is there a module comprising language principles, but also these principles are innate and are not learned.

\section{- Fodorian Modularity}

In the 1980s, however, Jerry Fodor revived the idea of the modularity of mind, although without the notion of precise physical localizability. Drawing from Noam Chomsky's idea of the language acquisition device and other work in

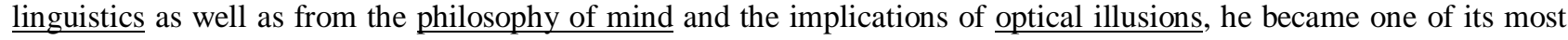
articulate proponents with the 1983 publication of Modularity of Mind. According to Fodor, a module falls somewhere between the behaviorist and cognitivist views of lower-level processes.

Behaviorists tried to replace the mind with reflexes which Fodor describes as encapsulated (cognitively impenetrable or unaffected by other cognitive domains) and non-inferential (straight pathways with no information added). Low level processes are unlike reflexes in that they are inferential. This can be demonstrated by poverty of the stimulus arguments in which the proximate stimulus, that which is initially received by the brain (such as the 2D image received by the retina), cannot account for the resulting output (for example, our 3D perception of the world), thus necessitating some form of computation.

In contrast, cognitivists saw lower level processes as continuous with higher level processes, being inferential and cognitively penetrable (influenced by other cognitive domains, such as beliefs). The latter has been shown to be untrue in some cases, such as with many visual illusions, which can persist despite a person's awareness of their existence. This is taken to indicate that other domains, including one's beliefs, cannot influence such processes.

For Fodor, in line with Chomsky's ideas, innateness is also a notion frequently associated with modularity drawing from his idea of LAD (Ingram, 2007). But whereas Chomsky locates modularity firmly within language ability, Fodor locates it in the mechanisms that support language processing. Fodor believes that the language faculty is modular in that the processing of linguistic input is not affected by higher cognitive domains or by other input systems; that is each 
module is autonomous from other modules. The language module, as cited in Carroll (2001), "processes only linguistic representations; in other words, the system encoding language is independent of the system used for encoding thought" (p. 251). Modules may have very limited access to other modules.

Fodor, according to Field (2004), views the mind as composed of a set of central modules which handle general operations such as attention and these central systems are supported by input modules which act autonomously and process sensory information such as language. The input systems are modular and, according to Wodak and Chilton (2005), have the following characteristics:

- Domain Specific: that is language perception modules only operate on linguistic structures, not with visual or social information.

- Informationally encapsulated: that is modules do not need to refer to other psychological systems in order to operate because modules have an innate basis.

- Fast: that is the processes are highly automatic.

- Shallow outputs: that is the output of modules is very simple.

- Limited accessibility: that is it is almost impossible to have access to the input modules.

Fodor, according to Perkins (2007), argues that various aspects of human cognition may be modules. In contrast to Chomsky's ideas who claim that the central system is itself constructed and is composed of a variety of modules, moreover, in contrast to Chomsky's belief that the central system is structured and tend to investigation, Fodor considers the central system to be unstructured and complicated to investigate. Fodor makes connections between his concept of modularity and that of Darwinian or computational modularity which are determined by genetic factors (Carruthers \& Chamberlin, 2000). According to Crystal (2008), the main difference between Chomsky's and Fodor's concept of language modularity is that in Fodor's modularity, mind is modular in a sense that it consists of different systems (modules), each with its own distinctive properties; whereas, in Chomsky's modularity, the language system is itself modular in a sense that it consists of a number of different subsystems which interact in different ways.

\section{- Massive Modularity}

Evolutionary psychologists propose that the mind is made up of genetically influenced and domain-specific, mental algorithms or computational modules, designed to solve specific evolutionary problems of the past. The definition of module has caused confusion and dispute. J. A. Fodor initially defined module as 'functionally specialized cognitive systems' that have nine features but not necessarily all at the same time. In his views modules can be found in peripheral processing such as low-level visual processing but not in central processing. Later he narrowed the two essential features to domain-specificity and information encapsulation. Frankenhuis and Ploeger (2007) write that domainspecificity means that "a given cognitive mechanism accepts, or is specialized to operate on, only a specific class of information". Information encapsulation means that information processing in the module cannot be affected by information in the rest of the brain. One example being awareness that certain optical illusion, caused by low level processing, are false not preventing the illusions from persisting.

Evolutionary psychologists instead usually define modules as functionally specialized cognitive systems that are domain-specific and may also contain innate knowledge about the class of information processed. Modules can be found also for central processing. This theory is sometimes referred to as Massive Modularity.

The concept of Massive Modularity has been proposed by evolutionary psychologists such as Tooby (Carruthers, 2008) evolve and are adapted to human evolution continuum. According to the massive modularity thesis, the mind is modular (in some sense) through and through, including the parts responsible for high-level cognition functions like belief fixation, problem-solving, planning, and the like. Originally articulated and advocated by proponents of evolutionary psychology (Sperber, 1994, 2002; Cosmides \& Tooby, 1992; Pinker, 1997; Barrett, 2005; Barrett \& Kurzban, 2005), the thesis has received its most comprehensive and sophisticated defense at the hands of Carruthers (2006). Before proceeding to the details of that defense, however, we need to consider briefly what concept of modularity is in play.

The main thing to note here is that the operative notion of modularity differs significantly from the traditional Fodorian one. Carruthers is explicit on this point:

If a thesis of massive mental modularity is to be remotely plausible, then by 'module' we cannot mean 'Fodormodule'. In particular, the properties of having proprietary transducers, shallow outputs, fast processing, significant innateness or innate channeling, and encapsulation will very likely have to be struck out. That leaves us with the idea that modules might be isolable function-specific processing systems, all or almost all of which are domain specific, whose operations aren't subject to the will, which are associated with specific neural structures, and whose internal operations may be inaccessible to the remainder of cognition. (Carruthers, 2006, p. 12)

Of the original set of nine features associated with Fodor-modules, then, Carruthers-modules retain at most only five: dissociability, domain specificity, mandatoriness, localizability, and central inaccessibility. Conspicuously absent from the list is informational encapsulation, the feature most central to modularity in Fodor's sense.

A second point, related to the first, is that defenders of massive modularity have chiefly been concerned to defend the modularity of central cognition (in some suitably robust sense, not necessarily Fodor's), taking for granted that the mind is modular around the edges (in Fodor's sense, or something like it). Thus, the thesis at issue for theorists like Carruthers might be best understood as the conjunction of two claims: first, that input systems are modular in a strong sense (that is, 
the positive strand of modest modularity), and second, that central systems are modular, but in a considerably weakened sense. In his (suitably massive) defense of massive modularity, Carruthers focuses almost exclusively on the second of these claims, and so will we. The centerpiece of Carruthers (2006) consists of three arguments for massive modularity: the argument from design, the argument from animals, and the argument from computational tractability. Let's briefly consider each of them in turn.

However, Fodor (2005) criticizes this hypothesis and claims that massive modularity of mind does little to explain adaptive psychological traits; moreover, it fails to explain human behavior in the environment. Thus, the assumptions underlying massive modularity are controversial and have been contested by some psychologists, philosophers and neuroscientists.

\section{CRitical LoOK at LANGUAge Modularity}

In Piaget's opinion, as cited in Jordan (2004), there is no modularity of mind. He believes that there is no innate language modularity (faculty) or any other specialized mechanism at work. He further added that "the child creates his own concepts through holistic interaction with the environment" (p. 140). Piaget argued that language is simply a manifestation of the more general skill which is acquired during general cognitive development as he goes through the stages of language acquisition; thus constructing his understanding of the world. Therefore, no special mechanism was required to account for first language acquisition. Karmiloff-Smith (2001), as cited in Cohen (1996), criticizes the concept of language modularity and specifically Fodor's assumption of the term. She argues that young children who suffer from brain damage are often capable of learning language just as well as children without problem. She claims that the MRI evidence shows that they just use a different part of the brain to use language. As an example, Christopher who was diagnosed as brain-damaged and has to live in care, is able to translate into and out of 16 languages. She further stresses on the role of holism or connectionism (i.e. the idea against Fodor's modularity which denies that language has specific components) and argues that even if language is identified to some degree with one module of the brain, this finding rejects Chomsky's idea of innate modularity in language. According to Fodor, language is domain specific; however, Jackendoff (2002) criticizes this claim and brings an example that for a second language learner whose language module according to Fodor is domain specific, however, in reality when a learner learns the second language, several different modules including vision and hearing are in interaction. Similar to this criticism and in contrast to Fodor's language module domain specificity, Sharwood-Smith (1994) concerns the role of Metalinguistic knowledge on SLA. Deacon (1999), as cited in Cohen (1996), rejects Chomsky idea of innate language modularity. He adds that there is no genetically installed linguistic black box in our brains whereas according to Darwin, languages, similar to human beings, evolve generation after generation resulting in a continuum from no language to the language we find now. Botterill and Carruthers (1999) believe that Fodor's concept of language modularity is too extreme because it restricts modularity only to the input system; whereas, they believe that a module is an integrated processing system with distinctive kinds of inputs and outputs. According to Carroll (2001), Fodor's concept of what a module is, is too crude. Because modularity, unlike what Fodor claims, does not necessarily entail autonomy. Separate processors might be processing the same representation. In summary, according to Perkins (2007), Fodor's model of modularity has impaired people's ability to imagine other possible areas of language faculty.

\section{IMPLICATIONS IN SLA}

According to Mitchell and Myles (2004), the role of an innate, domain specific language module in SLA has been much discussed in recent years and of course the issue hasn't been without controversy. If such innate mechanisms indeed exist, there are three logical possibilities:

- They continue to operate during second language acquisition in the same way that they make first-language learning possible. This implication was popularized in the SLA field by Krashen in the 1970s. Although Krashen's theoretical views have been criticized, this has by no means led to the disappearance of modular approach to account for SLA.

- After the acquisition of the first language in early childhood, these mechanisms stop operation, and second languages must be learnt by other mechanisms.

- The mechanisms that modularity provides for first language could be copied as a model when learning a second language.

Sharwood-Smith (1994) believes that, "SLA is itself modular because numerous learning mechanisms, including vocabulary, grammar ... contribute to the learning of different aspects of language" (p. 171). The idea of modularity, according to Taylor (1996), allows order to be distinguished from chaos; therefore, it helps us to regard the complexity of the L2 system as a set of simple ordered principles. Moreover, the modular study of second language acquisition suggests that the search for a structural approach to SLA should be abandoned in favor of a pragmatic one. On the other hand, according to Smith (1999), the study of modularity on SLA will shed light on the issue that whether linguistic modules develop independently of one another or whether they develop hand in hand. Sharwood-Smith (1994) further adds that "because according to modularity, mind is composed of different subsystems; therefore, when considering the possibility of native-like SLA ability. It may be possible for many learners to achieve native levels of second language 
proficiency in some subsystems but not others. As the result, language teachers can attempt to work on a particular linguistic module to help learners reach the native-like proficiency in that particular module they demand" (p. 18).

\section{CONCLUSION}

Interest in modularity is not confined to cognitive science and the philosophy of mind; it extends well into a number of interconnected fields. In philosophy of language, modularity has been remarkable in theorizing about linguistic communication, for example, in relevance theorists' suggestion that speech interpretation is a modular process (Sperber $\&$ Wilson, 2002). It has also been used demarcate the boundary between semantics and pragmatics. Though the success of these deployments of modularity theory is subject to dispute, their existence testifies to the ongoing relevance of the concept of modularity to philosophical inquiry across a variety of domains. There are many linguists today who support the concept of a distinctive language module in the mind. There are also those who argue that language competence itself is modular, with different aspects of language knowledge being stored and accessed in distinctive ways. However, there is still no general agreement on the number and nature of such modules.

\section{REFERENCES}

[1] Barrett, H. C. (2005). Enzymatic computation and cognitive modularity. Mind \& Language, 20, 259-287.

[2] Barrett, H. C., \& Kurzban, R. (2006). Modularity in cognition: Framing the debate. Psychological Review, 113, 628-647.

[3] Botterill, G., \& Carruthers, P. (1999). The philosophy of psychology. Cambridge: Cambridge University Press.

[4] Brook, A., \& Akins, K. (Eds.). (2005). Cognition and the brain: The philosophy and neuroscience movement. Cambridge: Cambridge University Press.

[5] Carroll, S. E. (2001). Input and evidence: The raw material of second language acquisition. Amsterdam: John Benjamins Publishing Company.

[6] Carruthers, P. (2006). The Architecture of the Mind. Oxford: Oxford University Press.

[7] Carruthers, P. (2008). On Fodor's problem. Oxford: Blackwell Publishing.

[8] Carruthers, P., \& Chamberlin, A. (Eds.). (2000). Evolution and the human mind: Modularity, language and meta-cognition. Cambridge: Cambridge University Press.

[9] Chomsky, N. (1972). Language and Mind: Enlarged Edition. New York: Harcourt Brace Jovanovich.

[10] Cohen, S. H. (1996). Modularity and principles and parameters: Avoiding the cognitively ugly. First Language, 16, 1-19.

[11] Cosmides, L., \& Tooby, J. (1992). Cognitive adaptations for social exchange. In J. Barkow, L. Cosmides \& J. Tooby (Eds.), The Adapted Mind (pp. 163-228). Oxford: Oxford University Press.

[12] Crystal, D. (2008). A dictionary of linguistics and phonetics $\left(6^{\text {th }}\right.$ ed.). Oxford: Blackwell Publishing.

[13] Dudai, Y. (2002). Memory from A to Z. Oxford: Oxford University Press.

[14] Ellis, R. (1997). Second language acquisition. Oxford: Oxford University Press.

[15] Field, J. (2004). Psycholinguistics: The key concepts. New York: Routledge.

[16] Fodor, J. A. (1990). A Theory of Content and Other Essays. Cambridge: MIT Press.

[17] Fodor, J. (2005). Reply to Steven Pinker 'So how does the mind work?' Oxford: Blackwell Publishing.

[18] Frankenhuis, W. E., \& Ploeger, A. (2007). Evolutionary psychology versus Fodor: Arguments for and against the massive modularity hypothesis. Philosophical Psychology, 20(6), 687-696.

[19] Gernsbacher, M. A., \& Foertsch, J. A. (1999). Three models of discourse comprehension. In S. Garrod \& M. Pickering (Eds.), Language processing. London: Psychology Press.

[20] Gregg, K. R. (2003). The stage of emergentism in second language acquisition. Second Language Research, 19(2), 95-128.

[21] Ingram, J. C. (2007). Neurolinguistics: An introduction to spoken language processing and its disorders. Cambridge: Cambridge University Press.

[22] Jenkins, L. (2000). Biolinguistics. Cambridge: Cambridge University Press.

[23] Jackendoff, R. (2002). Foundations of language: Brain, meaning, grammar, evolution. Oxford: Oxford University Press.

[24] Jordan, G. (2004). Theory construction in second language acquisition. Amsterdam: John Benjamins Publishing Company.

[25] McGilvray, J. (2005). Cambridge companion to Chomsky. Cambridge: Cambridge University Press.

[26] Mitchell, R., \& Myles, F. (2004). Second language learning theories (2 ${ }^{\text {nd }}$ ed.). New York: Oxford University Press.

[27] Perkins, M. (2007). Pragmatic impairment. Cambridge: Cambridge University Press.

[28] Pinker, S. (1997). How the Mind Works. New York: W. W. Norton \& Company.

[29] Smith, N. (1999). Chomsky: Ideas and ideals. Cambridge: Cambridge University Press.

[30] Sperber, D. (1994). The modularity of thought and the epidemiology of representations. In L. A. Hirschfeld \& S. A. Gelman (Eds.), Mapping the Mind (pp. 39-67). Cambridge: Cambridge University Press.

[31] Sperber, D. (2002). In defense of massive modularity. In I. Dupoux (Ed.), Language, Brain, and Cognitive Development (pp. 47-57). Cambridge: MIT Press.

[32] Sperber, D., \& Wilson, D. (2002). Pragmatics, modularity and mind-reading. Mind \& Language, 17, 3-23.

[33] Sugayama, K., \& Hudson, R. A. (Eds.). (2005). Word grammar. London: Continuum.

[34] Taylor, T. J. (1996). Generative linguistics: A historical perspective. New York: Routledge.

[35] Trask, R. L. (1999). Key concepts in language and linguistics. New York: Routledge.

[36] Van Valin, R. (1991). Functionalist linguistic theory and language acquisition. First Language, 11, 7-40.

[37] Wodak, R., \& Chilton, P. (Eds.). (2005). A new agenda in critical discourse analysis. Amsterdam: John Benjamins Publishing Company.

[38] Zobl, H. (1989). Modularity in adult L2 acquisition. Language Learning, 39(1), 49-79. 


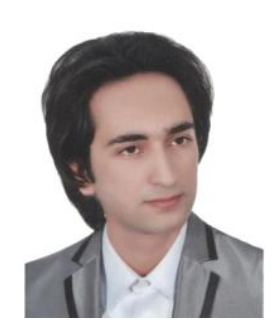

Houman Bijani is a Ph.D. candidate in TEFL from Islamic Azad University (Science and Research Branch). He got his M.A. in TEFL from Allameh Tabataba'i University in 2009 as a top student. He was awarded the TKT (Teaching Knowledge Test) certificate from Cambridge University in 2009. Currently, he is a faculty member at Zanjan Islamic Azad University. He has published several papers in national and international journals and has presented a number of papers in conferences. His areas of interest include testing, writing assessment and teacher education.

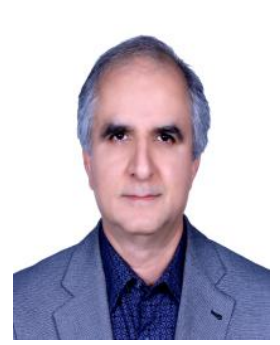

Alaeddin Nahvi is a faculty member at Tehran Art University in Iran. He received his B.A. in English Literature from Calicut University, India in 1990 and his M.A. in English Literature from Bombay University, India in 1993. He has translated several books and papers in English and Persian. His main interests are Art and English Language. 